brook PA, Ehsani AA. Left ventricular diastolic filling and its association with age. Am J Cardiol 1986;58:531-5.

26. Yellin EL, Nikolic S, Frater RWM. Left ventricular filling dy namics and diastolic function. Prog Cardiovase Dis 1990; 32:879-86.

27. Bahler RC, Martin P. Effects of loading conditions and inotropic state on rapid filling phase of left ventricle. Am J Physiol 1985;248:H523-33.

28. Verani MS, George SE, Leon CA, et al. Systolic and diastolic ventricular performance at rest and during exercise in heart transplant recipients. J Heart Transplant 1988;7:145-51.

29. Lorell BH, Turi Z, Grossman W. Modification of left ventricular response to pacing tachycardia by nifedipine in patients with coronary artery disease. Am J Med 1981;71:667-774.

30. Starling MR, Dell'Italia LJ, Walsh RA, Little WC, Benedetto AR, Nusynowitz ML. Accurate estimates of absolute left ventricular volumes from equilibrium radionuclide angiographic count data using a simple geometric attenuation correction. .J Am Coll Cardiol 1984;3:789-98
31. Rabinowitz B, Chuck L, Kligerman M, Parmley WW. Positive inotropic effects of methoxamine: evidence for alpha-adrenergic receptors in ventricular myocardium. Am J Physiol 1975; 229:582-5.

32. Heyndrickx GR, Boettcher DH, Vatner SF. Effects of angiotensin, vasopressin, and methoxamine on cardiac function and blood flow distribution in conscious dogs. Am .J Physiol 1976;231:1579-87.

33. Bonow RO, Leon MB, Rosing DR, Kent DM, Lipson LC, Bacharach SL, Green MV, Epstein SE. Effects of verapamil and propranolol on left ventricular systolic function and diastolic filling in patients with coronary artery disease: radionuclide angiographic studies at rest and during exercise. Circulation 1981;65:1337-50.

34. Bonow RO, Dilsizian V, Rosing DR, Maron BJ, Bacharach SL, Green MV. Verapamil-induced improvement in left ventricular diastolic filling and increased exercise tolerance in patients with hypertrophic cardiomyopathy: short-and long-term effects. Circulation 1985;72:853-64.

\title{
The angle of incidence of the ultrasonic beam: A critical factor for the image quality in intravascular ultrasonography
}

\begin{abstract}
The effects of the angle of incidence of the ultrasound beam on the image quality were studied in 21 pressurized arterial specimens examined with a $30 \mathrm{MHz}$ intravascular ultrasonographic catheter. When the ultrasonographic catheter was in an eccentric position in the vessel lumen, the videodensity of the segments of the vessel wall with the least favorable angle of interrogation (a shift of $49 \pm 6$ degrees from the tangent to the tissue surface) was $27 \% \pm 19 \%$ lower than the videodensity measured with the catheter in the center of the lumen. When the catheter was placed in a position that was not parallel to the long axis of the vessel, a further decrease was observed, especially in the vessel wall opposite the position of the catheter. An artificial dissection was induced in eight specimens. Dropouts that involved the dissection plane and the underlying structures were produced with positions of the echographic catheter inducing a narrow angle between ultrasound beam and dissection plane. These experimentally induced artifacts were compared with similar findings from the in vivo evaluation of peripheral and coronary arteries. The angle of incidence of the ultrasound beam is a major determinant of the image quality in intravascular ultrasonography. Angle-dependent artifacts occur with eccentric and noncoaxial positions of the ultrasonographic catheter and, in particular, with imaging of large intraluminal dissections. Awareness of this problem may prevent image misinterpretation and has relevance for future improvement of catheter technology and design. (AM HEART J 1993;125:442.)
\end{abstract}

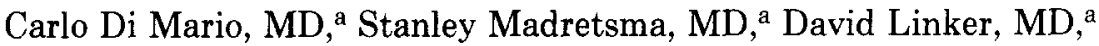

Salem H. K. The, MD, ${ }^{b}$ Nicolaas Bom, PhD, ${ }^{b}$ Patrick W. Scrruys, MD, ${ }^{b}$

Elma J. Gussenhoven, MD, ${ }^{\mathrm{b}}$ and Jos R. T. C. Roelandt, MD

Rotterdam, The Netherlands

From athe Department of Cardiology, Thoraxcenter, Erasmus University Rotterdam and b the Interuniversity Cardiology Institute, The Netherlands Received for publication Apr. 20, 1992; accepted Aug. 14, 1992.

Reprint requests: Carlo Di Mario, MD, Thoraxcentre, Ee 2332 P.O. Box 1738, 3000 DR Rotterdam, The Netherlands.

Dr. C. Di Mario, Division of Cardiology, Vicenza, Italy, is the recipient of the European Society of Cardiology Research Fellowship 1991.
Images that are obtained with intravascular ultrasonography show great variability in quality and create problems in interpretation. ${ }^{1-3} \mathrm{An}$ ideal, perpendicular angle of incidence of the ultrasound beam to the vessel wall requires a catheter position in the center of the lumen and parallel to the long axis of the vessel. In practice, several factors (e.g., curvature of 

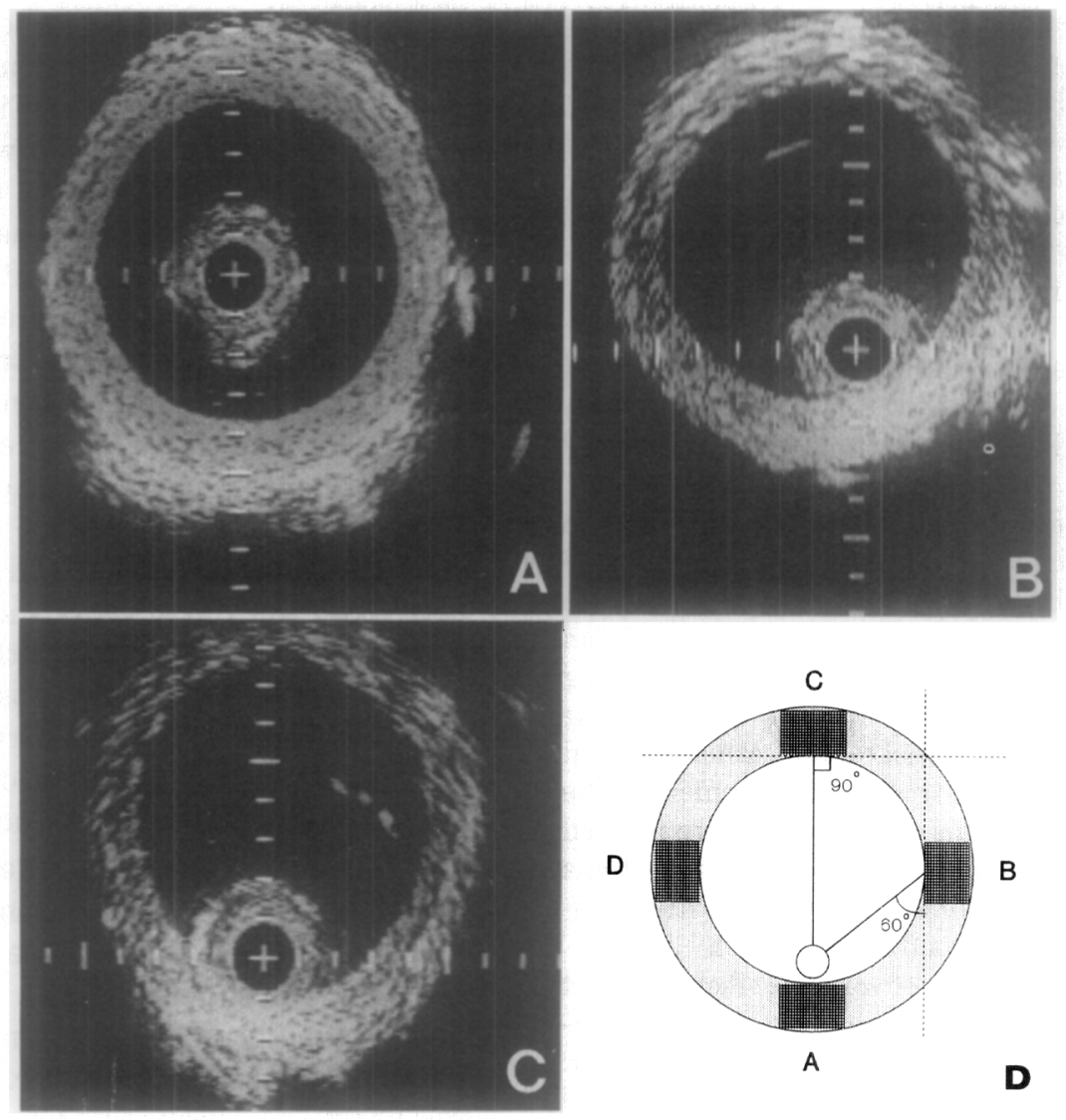

Fig. 1. Three intravascular ultrasonographic inages of a common carotid artery (elastic type of artery as determined from histologic studies) examined in vitro, with internal pressure maintained at $100 \mathrm{~mm} \mathrm{Hg}$. $A$, The catheter is in the center of the vessel lumen, and the vessel wall shows a uniform intensity. B, The catheter is eccentric in the lumen but parallel to the long axis of the vessel. Note the well-preserved circular shape of the lumen, with a maximal videodensity of the vessel wall in the segment beside the catheter and a minimal videodensity in the lateral walls. $C$, When the catheter is not parallel to the long axis of the vessel, the lumen becomes elliptic, with a further decrease in videodensity of the vessel wall and especially of the segment opposite the catheter (calibration $=1 \mathrm{~mm}$ ). $\mathbf{D}$, The drawing shows the position of the regions of interest in which the videodensity has been measured. ${ }^{4}$ The angle of incidence of the ultrasound beam is measured as the angle included between the tangent to the midpoint of the intimal surface of the segment of interest and the line joining this point with the center of the catheter.

the vessel, wall irregularities, or dissections) may preclude this optimal situation. In an attempt to improve interpretation of in vivo intravascular ultrasonographic images we reproduced and quantitatively studied angle-dependent artifacts in in vitro pressurized arteries with and without artificially induced arterial wall dissections.

\section{METHODS}

Material. Twenty-one arterial specimens of 5 to $6 \mathrm{~cm}$ in length were obtained from 13 subjects at autopsy ( 18 common or external iliac arteries and 3 common carotid arteries). One end of the arterial specimen was closed, and the other was tied to a $7 \mathrm{~F}$ valved sheath. Saline solution was injected through the side arm of the sheath, and the pressure, which was monitored with a Gould P23ID pressure transducer (Viggo-Spectramed Inc., Critical Care Div.,
Oxnard, Calif.), was increased to $100 \mathrm{~mm} \mathrm{Hg}$ and maintained at this level throughout the examination. A 5F 30 $\mathrm{MHz}$ rotating element ultrasonographic catheter (DuMed, Rotterdam, The Netherlands $)^{3}$ was advanced to the midpoint of the arterial segment through the valved sheath. The internal diameters of the examined vessels were measured at $100 \mathrm{~mm} \mathrm{Hg}$ with a previously described analysis program ${ }^{4}$ and ranged from 6.2 to $8.9 \mathrm{~mm}$ (mean, $7.4 \pm 1.4 \mathrm{~mm}$ ).

Intravascular ultrasonographic examination. Crosssectional imaging was performed with the catheter positioned both in the center of the vessel lumen and close to the vessel wall (Fig. 1, $A$ and $B$ ). The time-gain compensation was unchanged throughout the examination procedure. Subsequently, the closed end of the vessel was raised, which simulated a curvature of 10 to 50 degrees between the proximal segment of the vessel that contained the 
echographic catheter and the imaged distal segment of the vessel (Fig. 1, C). A previously described computerized system ${ }^{5}$ was used to calculate the mean videodensity of four regions of interest, which were situated along the circumference of the vessel wall as shown in Fig. 1, D. These measurements were performed with the catheter positioned centrally in the vessel lumen, close to the vessel wall (eccentric position), and noncoaxial with the long axis of the vessel. The angle of interrogation of these regions was measured as the angle between the tangent to the vessel wall and the line that connected the midpoint of the intimal contour of the region of interest with the center of the catheter (Fig. 1, D).

In 8 of these 21 specimens an artificial dissection was created by careful separation of the internal and external parts of the vessel wall through half of the circumference of the vessel. The specimens were then embedded in an agar-agar solution with the induced flap largely protruding inside the vessel lumen. Cross-sectional ultrasonic imaging was performed with the ultrasonographic catheter placed in various positions within the true and false lumens of the vessel. The examined positions of the vessel were marked with India ink and corresponding histologic cross-sections ( $5 \mu \mathrm{m}$ in thickness) were obtained and stained with hematoxylin azophloxine and Verhoeff's Elastin van Gieson.

Statistical analysis. Analysis of variance (Fisher's exact test) was used to detect the presence of significant differences in videodensity for each position of the transducer. When this test was statistically significant (eccentric and noncoaxial positions) a paired $t$ test was used to compare each pair of regions of interest. An unpaired $t$ test was used to compare the difference in videodensity of corresponding areas that were examined with different positions of the transducer.

\section{RESULTS}

As determined from histologic examination, 13 arteries were classified as muscular, 5 as elastic, and 3 as transitional according to previously reported criteria. ${ }^{6} \mathrm{~A}$ thin layer of diffuse fibrous intimal thickening was observed in 19 arteries. Two arteries showed an atherosclerotic plaque in the studied cross-section. In the eight arteries that were used as a model of wall dissection, the dissected wall was composed of a thickened intimal layer in two cases, intima and the full thickness of the medial layer in three cases, and intima and part of the media in three cases. With the exception of the two arteries with focal atherosclerotic plaques, the videodensity of the four regions of interest (Fig. 1, D) was similar when the catheter was in a central position in the vessel lumen (Fig. 2).

Eccentric position of the catheter. When the catheter was positioned close to the vessel wall, the videodensity was higher in the segment close to the ultrasonographic transducer (segment $A$ ) and was lower in the opposite vessel segment (segment C) (Fig. 2) $(p<0.01)$. The maximal reduction in videodensity, however, was not observed in the position of maximal distance from the transducer but in the lateral segments (segments B and D in Fig. 2) $(p<0.01)$. For these two areas the angle between the ultrasound beam and the examined vessel segment was $49 \pm 6$ degrees, and the mean videodensity was $27 \% \pm 19 \%$ lower than the videodensity that was measured when the catheter was in a central position $(p<0.02)$.

Noncoaxial orientation of the catheter. In the model that was used in this study, when the catheter was not parallel to the long axis of the imaged vessel, the catheter was also in an eccentric position in the vessel lumen (Fig. 1,C). Thus the observed changes in videodensity were the combined result of the changes in two planes of the angle of incidence of the ultrasound beam. In comparison with the measurements in an eccentric but coaxial position, a further decrease in videodensity was observed, especially in the segment opposite the position of the catheter (NS).

Wall dissection. In the presence of a dissected flap inside the vessel lumen, extremely narrow angles between ultrasound beam and plane of dissection could be induced by manipulating the catheter both in the true lumen and the false lumen (Fig. 3). In these positions, the dissected flap could not be visualized with ultrasonography. Furthermore, the dissected flap concealed the underlying lumen and vessel wall so that the identification of dimensions and shape of the true and false lumens became impossible. These effects were dependent only on the angle of incidence of the ultrasound beam. Thickness, severity of intimal fibrosis, and presence or absence of medial layer in the dissected flap did not influence the results.

Atherosclerotic plaques. Fig. 4 shows that the delineation and characterization with intravascular ultrasonography of the atherosclerotic plaque is more difficult when this structure is imaged with an unfavorable angle of incidence.

\section{DISCUSSION}

The ratio of the dimensions of the wavelength of the incident beam to the dimensions of the target structure is a major determinant of the backscattered power. If the dimensions of the target are much smaller than those of the beam wavelength, the object behaves as an ideal point scatterer, and its backscatter is similar in all directions. On the contrary, larger structures cause a directional backscatter that depends on the shape of these structures. For a simple flat interface, the backscattered energy decreases if the angle between the ultrasonic beam and the normal to the tissue surface increases. When these basic principles are applied to intravascular ultra- 


\section{$*$ NON-COAXIAL $\left(20^{\circ}\right) \rightarrow$ CENTRAL $\triangle$ ECCENTRIC}

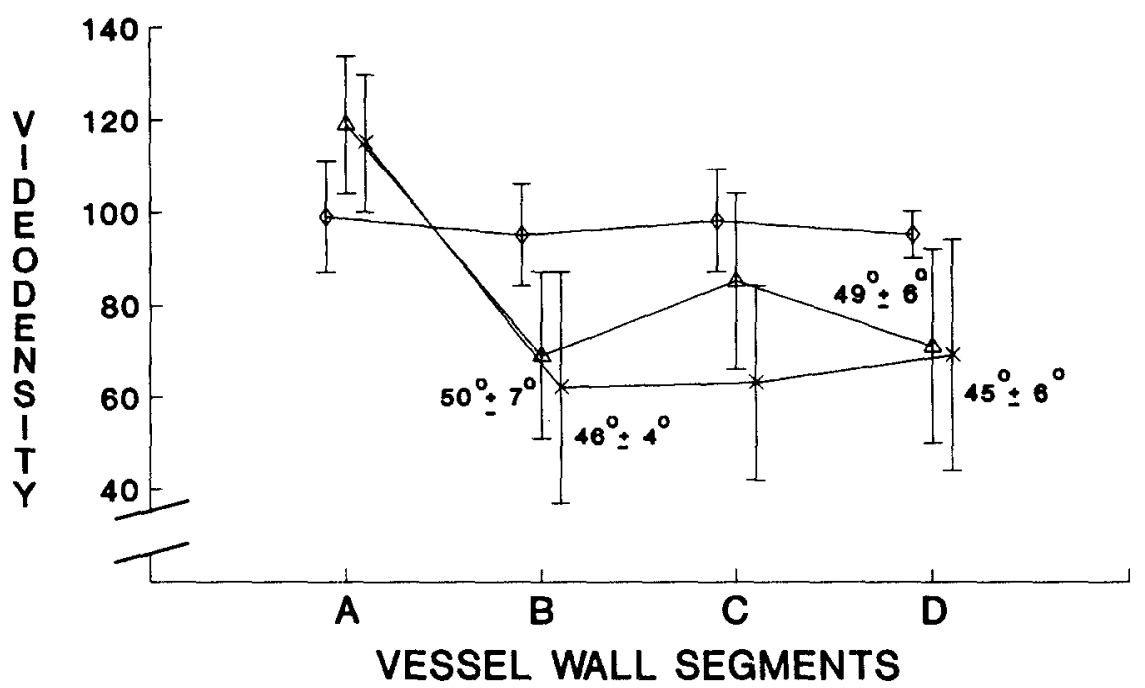

Fig. 2. The graph shows the videodensity of the four selected regions of interest (as indicated in Fig. 1, $D$ ) of 21 pressurized specimens. The videodensity is measured in arbitrary units. With the catheter in a central position (upper line) the regions of interest show a similar videodensity. The eccentricity of the catheter induces (middle line) an angle of $49 \pm 6$ degrees between the ultrasound beam and the tangent to the vessel wall in regions $B$ and $D$ and a consequent mean reduction of $27 \%$ of their videodensity. The noncoaxial position of the catheter, with an angle of 20 degrees with the long axis of the vessel (lower line), induces a further decrease in videodensity, especially in position $C$ (opposite wall). The angles between ultrasound beam and tissue surface in segments $B$ and $D$ (lateral walls) are measured for eccentric positions of the catheter according to the drawing in Fig. 4.

sonographic imaging, red blood cell dimensions are similar to the wavelength of the high-frequency (30 $\mathrm{MHz}$ ) transducers which are used so that the backscatter of blood can be considered omnidirectional. The behavior of the vessel wall, on the contrary, is inhomogeneous and dependent on the dimension, shape, and orientation of its components, with the presence of various levels of directional backscatter. The uniform directional backscatter of the red blood cells explains why areas of vascular lumen are well delineated in Fig. 5, $A$ and $B$, whereas the adjacent vessel walls show large dropouts.

In vitro studies. Picano et al, ${ }^{7}$ several years before the development of intravascular ultrasonography, reported that a strongly angle-dependent backscatter is typical of calcific and fibrous plaque components, whereas fatty plaques have a less directive pattern. More recently, de Kroon et al. ${ }^{8}$ showed an anisotropic behavior of the muscular and elastic medial layers, with a larger angle-dependent reduction of the integrated backscattered power in planes that are parallel to the long axis of the fibers than in planes that are perpendicular to this axis. In these studies, which were carried out with acoustic microscopes, the focus was on potential interest in these changes for tissue characterization. Nishimura et al. ${ }^{9}$ used intravascular ultrasonographic catheters to measure circular wells of known diameter. They observed that the luminal dimensions did not change with the position of the catheter as long as it was parallel to the long axis of the well. A noncoaxial orientation at an angle of 30 degrees, on the contrary, resulted in an increase of $20 \%$ of the luminal area, which became elliptical.

Our experience suggests that eccentric or noncoaxial positions of the catheter are not only important for the accuracy of the measurements of the lumen area but also that they also influence the quality of the echographic images of both the normal wall and the atherosclerotic plaques. The lack of steerability of the present generation of ultrasonographic catheters precludes an effective correction of eccentric or noncoaxial catheter positions. Improvement in catheter technology and design (steerability of the catheter, multiplane imaging) is desirable to overcome the present limitations of intravascular ultrasonography. A model of artificial dissection was used to understand the images after balloon angioplasty. The complexity of these images is caused by the very narrow angle between the dissected wall and the ultra- 


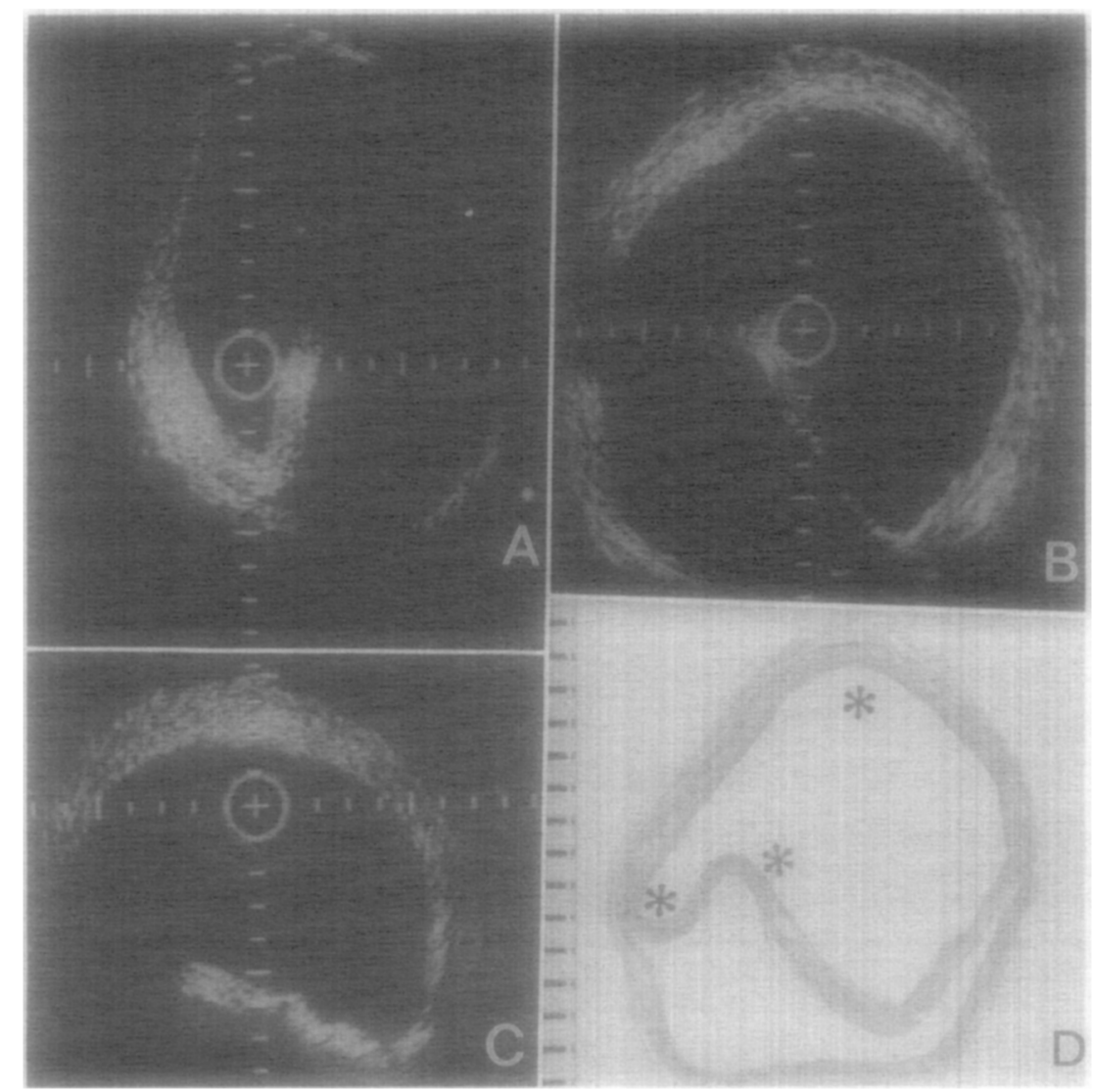

Fig. 3. Panels A-C show three intravascular ultrasonic cross-sections of an iliac artery in which an artificial dissection of the vessel wall is largely protruding inside the lumen. Asterisks mark the positions of the echographic catheter in the corresponding histologic cross-section (panel D) for orientation. Complex dropouts of the dissection plane and the underlying vessel wall are induced by narrow angles of incidence of the ultrasound beam on the dissected flap (calibration $=1 \mathrm{~mm}$ ). $\mathbf{D}$, The histologic cross-section shows that the dissection flap consists of a thickened fibrotic intimal layer and part of the degenerated muscular media (Verhoeff"s stain; calibration $=1 \mathrm{~mm}$.)

sound beam. The failure to image the vessel wall underlying these dissection flaps is likely to be the result of the decrease in ultrasound energy as it crosses the dissected wall in both directions of the wave propagation (from transducer to underlying structures and vice versa) above a critical angle of incidence of the ultrasound beam.

In vivo studies. An eccentric position of the ultrasonographic catheter, close to the intimal surface of the vessel, is the rule rather than the exception in intravascular ultrasonography. The angle between the ultrasound beam and the vessel wall depends on the dimension of the lumen, and wider angles are observed in larger vessels. The coronary arteries have a small diameter (normally 2 to $4 \mathrm{~mm}$ ) relative to the diameter of the currently used ultrasonographic catheters (1.0 to $1.6 \mathrm{~mm}$ ) so that presence and severity of angle-dependent artifacts in these vessels are minimized. In larger vessels, however, partial or complete dropouts of the vessel wall may occur. The echogenicity and the omnidirectional backscatter of blood may allow the tracing of the contour of the vessel lumen despite the presence of relatively large circumferential dropouts of the vessel wall. Complex artifacts, which are due to the presence of large intraluminal dissections, have been common in our experience in patients who were undergoing balloon dilatation of peripheral arteries. Examinations of adjacent cross-sections and knowledge of the principles that underlie the specific features of these images may facilitate their correct interpretation. Unfavorable or eccentric catheter positions have already been reported as a cause of failure or overestimation and distortion of lumen area in intravascular ultrasonographic studies of both peripheral ${ }^{10-12}$ and coronary vessels..$^{13-20}$ The peculiar characteristics of the artifacts that we observed with large protruding dissections (Fig. 5), however, have not been previ- 


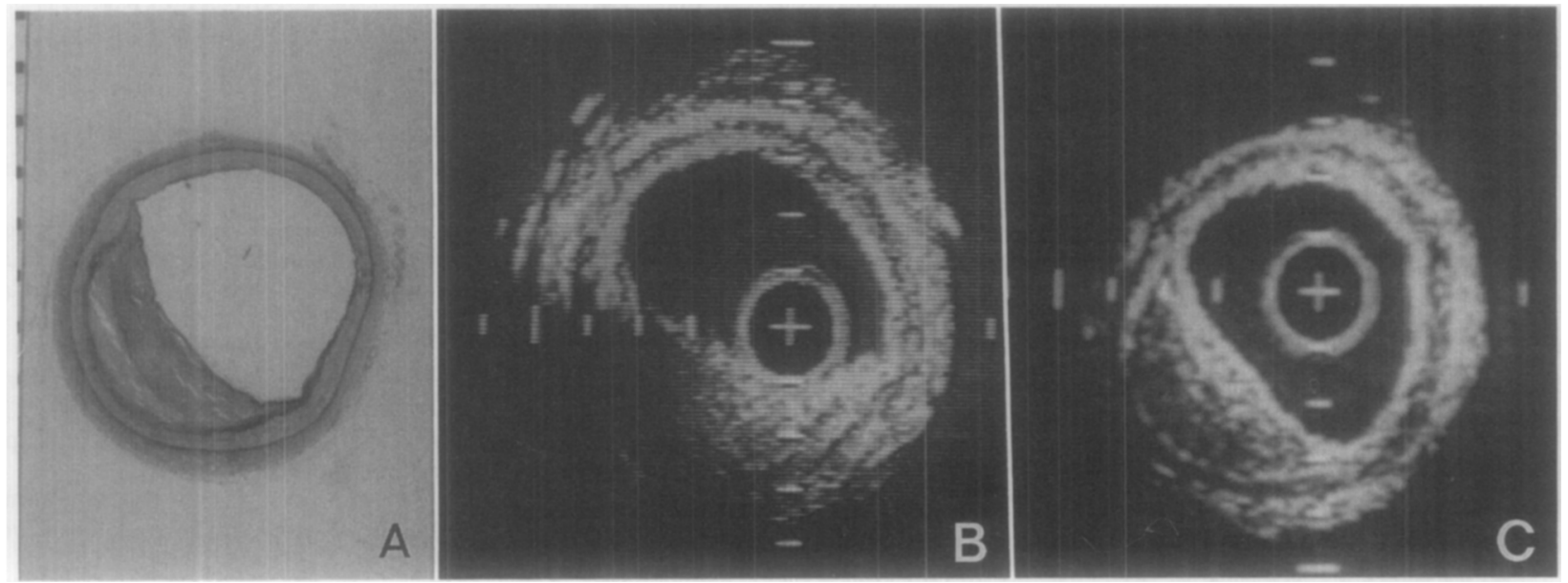

Fig. 4. A, Histologic cross-section of an external iliac artery, with a semicircular plaque composed of stratified lamina of dense fibrous tissue and a well-developed muscular media. (Verhoeff's stain; calibration $=1 \mathrm{~mm}$.) $\mathbf{B}$, and $\mathbf{C}$, Corresponding intravascular ultrasonographic cross-sections with the catheter adjacent to the vessel wall and in the center of the lumen. The atherosclerotic plaque is well delineated when the ultrasound beam has a perpendicular orientation, whereas identification of the plaque contours becomes impossible with a tangential orientation of the ultrasound beam to the tissue surface. Note the sonolucent band corresponding to the muscular media.

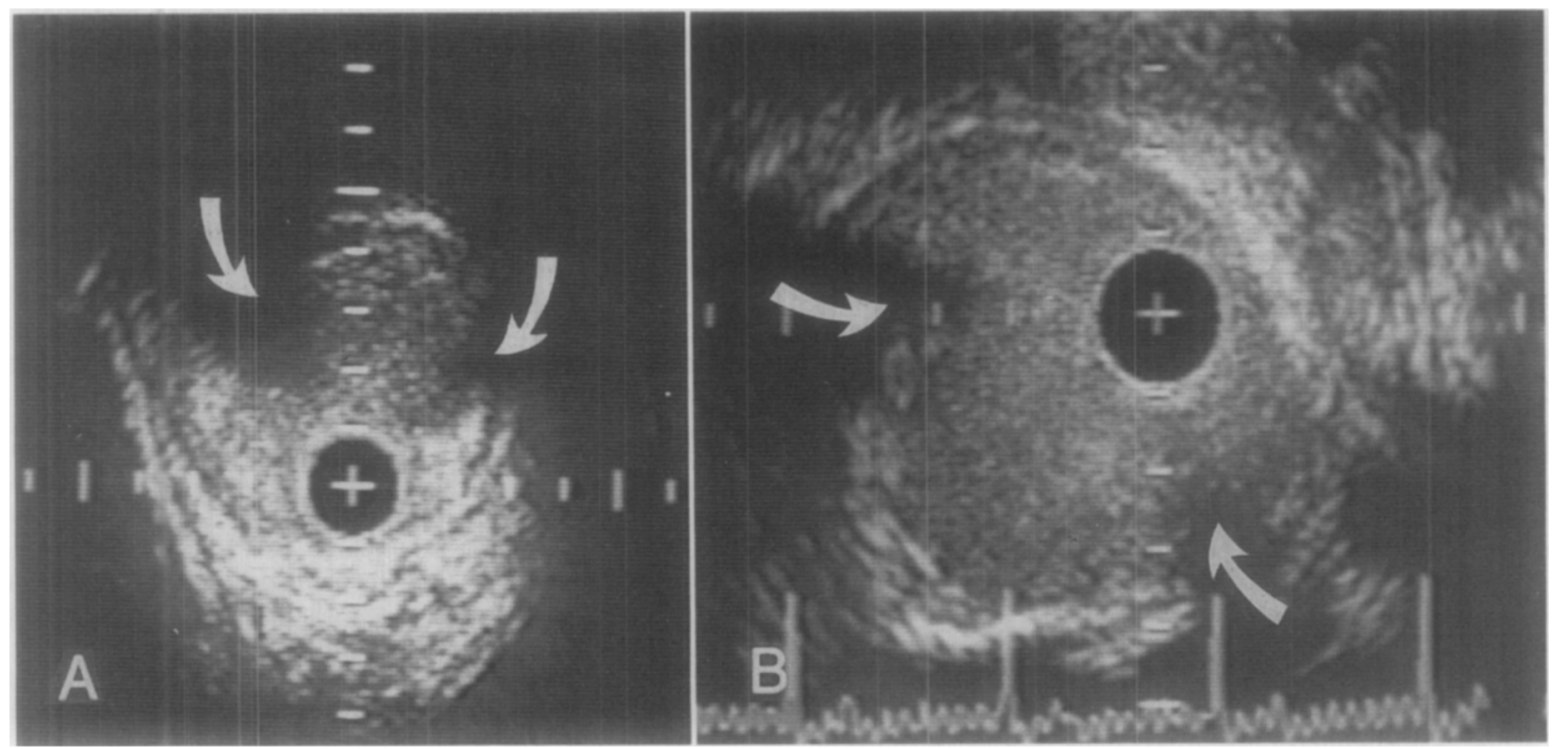

Fig. 5. A, Intravascular ultrasonographic image of a superficial femoral artery after balloon dilatation. The catheter is positioned in a crescent-shaped lumen, which is included between the vessel wall and a large intimal flap. Note that the false lumen and the opposite wall behind the dissection are visualized only in the area of perpendicular orientation to the ultrasound beam. A dropout of the underlying structures is observed in the presence of a narrow angle of incidence of the ultrasound beam on the dissection plane ( $a r$ rows). B, Intravascular ultrasonographic image of a superficial femoral artery after balloon dilatation. Large dropouts of the two extremities of the dissected plane (curved arrows) and of the underlying vessel wall and lumen cause interpretation problems. Note that the omnidirectional backscatter of blood clearly delineates the half-moon shape of the true lumen.

ously described. We observed these changes only in peripheral vessels, probably because in the smaller coronary vessels the protruding plaques that were dissected from the balloon inflation were pushed against the opposite wall by the ultrasonographic catheter, thus avoiding the development of significant angle-dependent artifacts.

Conclusions. The angle of incidence of the ultra- 
sound beam significantly affects the quality of the echographic image in intravascular ultrasonography and explains the image deterioration that occurs with eccentric or noncoaxial positions of the catheter and particularly in the presence of intraluminal dissection flaps that protrude inside the lumen. Awareness of the importance of this phenomenon may improve image acquisition and prevent misinterpretation of intravascular ultrasonographic images. Future developments in design of intravascular ultrasonographic catheters that allow steerability or multiplane imag. ing may improve image acquisition and circumvent these limitations.

We thank M. G. M. de Kroon, $\mathrm{PhD}$, N. de Jong, $\mathrm{PhD}$, E. Boersma, $\mathrm{PhD}, \mathrm{C}$. Lancèe, $\mathrm{PhD}$, and J. Oomen, $\mathrm{PhD}$, for help, suggestions, and criticisms in the preparation of this manuscript. The images shown in Fig. 5 were obtained by Dr. H. Pieterman during intravascular ultrasonographic studies, which were carried out in the Radiology Department, Academic Hospital RotterdamDijgzigt. We thank Mrs. Coby Peekstok for preparing the histologic sections and Dr. R. J. van Suylen for interpreting them.

\section{REFERENCES}

1. Pandian NG. Intravascular and intracardiac ultrasound imaging: an old concept now on the road to reality. Circulation 1989;80:1091-4.

2. Pandian NG, Kreis A, Brockway B, Isner JM, Sacharoff A, Boleza E, Caro R, Muller D. Ultrasound angioscopy: real time, two-dimensional, intraluminal ultrasound imaging of blood vessels. Am J Cardiol 1988;62:493-4.

3. Roelandt JR, Bom N, Serruys PW, Gussenhoven EJ, Lancèe $\mathrm{CT}$, Sutherland GR. Intravascular high-resolution real time cross-sectional echocardingraphy. Echocardingraphy 1989;6:9. 16.

4. Wenguang L, Gussenhoven WJ, Zhong Y, The SHK, Di Mario C, Madretsma S, van Egmond F, de Feyter PJ, Pieterman H, van Urk H, Rijsterborgh $\mathrm{H}$, Bom N. Validation of quantitative analysis of intravascular ultrasound images. Int J Card Imaging 1991;6:247-54.

5. de Jong N, Mittertreiner WH, Ligvoet KM, Ten Cate FJ. A computerized system that uses high-frequency data for analysis of myocardial contrast echocardiograms. J Am Soc Echocardiogr 1990;3:99-105.

6. Di Mario C, The SHK, Madretsma S, van Suylen RJ, Wilson R, Bom N, Serruys PW, Gussenhoven WG, Roelandt JRTC. Detection and characterization of vascular lesions by intravascular ultrasound. An in-vitro correlative study with histology. J Am Soc Echocardiogr 1992;19:135-46.
7. Picano E, Landini L, Distante A, Salvadori M, Lattanzi F, Masini M, L'Abbate A. Angle-dependence of ultrasonic backscatter in arterial tissues. A study in-vitro. Circulation 1985;72:572-6.

8. de Kroon MGM, van der Wal LF, Gussenhoven WJ, Bom N. Angle-dependent backscatter from the arterial wall. Ultrasound Med Biol 1991;17:121-6.

9. Nishimura RA, Edwards WD, Warnes CA, Reeder GS, Holmes DR, Tajik AJ, Yock PG. Intravascular ultrasound imaging: in-vitro validation and pathologic correlation. $J$ Am Coll Cardiol 1990;16:145-54.

10. Isner JM, Rosenfield JO, Losordo DW, Kelly S, Palefski P, Langevin RE, Razvi S, Pastore JO, Kosowsky BD. Percutaneous intravascular ultrasound as adjunct to catheter-based interventions: preliminary experience in patients with peripheral vascular disease. Radiology 1990;175:61-70.

11. Nishimura RA, Welch TJ, Stanson AW, Sheedy PF, Holmes DR. Intravascular ultrasound of the distal aorta and iliac vessels: initial feasibility studies. Radiology 1990;176:523-5.

12. Gussenhoven WJ, Frietman P, The SHK, Egmond van FC, van Suylen F, Lancèe CT, Urk van H, Roelandt J, Bom N. Assessment of medial thinning in atherosclerosis with intravascular ultrasound. Am J Cardiol 1991;68:625-32.

13. Tobis JM, Mallery JA, Mahon D, Lehmann K, Zalesky P, Griffith J, Gessert J, Moriuchi M, McRae M, Dwyer ML, Greep $\mathrm{N}$, Henry WL. Intravascular ultrasound imaging of human arteries in vivo. Circulation 1991;83:913-26.

14. Yock PG, Fitzgerald PJ, Linker DT, Angelsen BAJ. Intravascular ultrasound guidance for catheter-based coronary interventions. J Am Coll Cardiol 1991;17:39B-45B

15. Nissen SE, Gurley JC, Grines CL, Booth DC, McClure R, Berk M, Fisher C, DeMaria AN. Intravascular ultrasound assessment of lumen size and wall morphology in normal subjects and patients with coronary artery disease. Circulation 1991; 84:1087-99.

16. Werner GS, Sold G, Buchwald A, Wiegand V. Intravascular ultrasound imaging of human coronary arteries after percutaneous transluminal angioplasty: morphologic and quantitative assessment. AM HEART J 1991;122:212-20.

17. StGoar FG, Pinto F.I, Alderman EL, Fitzgerald P.J, Stadius ML, Popp RL. Intravascular ultrasound of angiographically normal coronary arteries: an in-vivo comparison with quantitative angiography. J Am Coll Cardiol 1991;18:952-8.

18. Pinto F, StGoar FG, Fischell TA, Stadius ML, Valantine HA Alderman EL, Popp RL. Nitroglycerin-induced coronary vasodilatation in cardiac transplant recipients. Evaluation with in vivo intracoronary ultrasound. Circulation 1992;85:69-77.

19. Honye J, Mahon DJ, White CJ, Ramee SR, Wallis JB, Al-Zarka A, Tobis JM. Morphological effects of coronary balloon angioplasty in vivo assessed by intravascular ultrasound imaging. Circulation 1992:85:1012-25.

20. StGoar FG, Pinto FJ, Alderman E, Valantine HA, Schroeder JS, Stinson EB, Popp RL. Intracoronary ultrasound in cardiac transplant recipients. In vivo evidence of "angiographically silent" intimal thickening. Circulation 1992;85:979-87. 